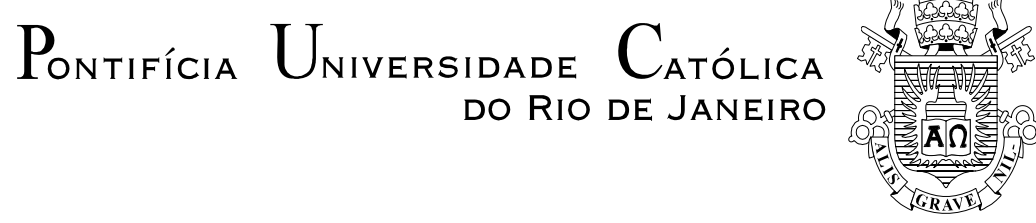

Norma Cavalcanti Pontilhão Vieira

Da neurose de angústia ao pânico:

sobre as angústias atuais

Dissertação de Mestrado

Dissertação apresentada como requisito parcial para obtenção do grau de Mestre pelo Programa de Pósgraduação em Psicologia do Departamento de Psicologia da PUC-Rio.

Orientador: Prof. Marcus André Vieira

Rio de Janeiro

Março de 2012 


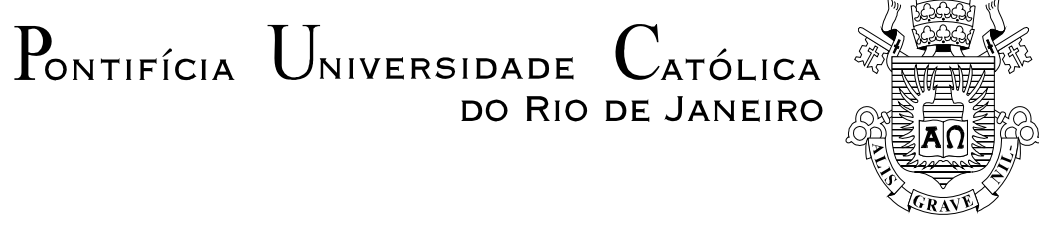

Norma Cavalcanti Pontilhão Vieira

\section{Da neurose de angústia ao pânico: sobre as angústias atuais}

Dissertação apresentada como requisito parcial para obtenção do grau de Mestre pelo Programa de Pós-Graduação em Psicologia Clínica do Departamento de Psicologia do Centro de Teologia e Ciências Humanas da PUC-Rio. Aprovada pela Comissão Examinadora abaixo assinada.

Prof. Marcus André Vieira

Orientador

Departamento de Psicologia - PUC-Rio

Profa. Ana Maria de Toledo Piza Rudge

Departamento de Psicologia - PUC-Rio

Profa. Angélica Bastos de Freitas Rachid Grimberg Instituto de Psicologia - UFRJ

Profa. Denise Berruezo Portinari Coordenadora Setorial de Pós-Graduação

e Pesquisa do Centro de Teologia e Ciências Humanas - PUC-Rio

Rio de Janeiro, 02 de março de 2012. 
Todos os direitos reservados. É proibida a reprodução total ou parcial do trabalho sem autorização da autora, do orientador e da universidade.

\section{Norma Cavalcanti Pontilhão Vieira}

Graduou-se em Bacharelado em Psicologia em 2008 e Formação de Psicólogo em 2009 pela UFRJ. Desenvolveu junto ao Instituto de Psicologia da UFRJ, como Bolsista CNPq, pesquisa na área de Psicanálise. Bolsista CAPES do Programa de PósGraduação em Psicologia Clínica da PUC-Rio no período de 2010-2011

Ficha Catalográfica

Vieira, Norma Cavalcanti Pontilhão

Da neurose de angústia ao pânico: sobre as angústias atuais / Norma Cavalcanti Pontilhão; orientador: Marcus André Vieira. - 2012.

107 f. ; $30 \mathrm{~cm}$

Dissertação (mestrado) - Pontifícia Universidade Católica do Rio de Janeiro, Departamento de Psicologia, 2012.

Inclui bibliografia

1. Psicologia - Teses. 2. Angústia. 3. Perigo. 4. Objeto a. 5. Gozo. 6. Pânico. I. Vieira, Marcus André. II. Pontifícia Universidade Católica do Rio de Janeiro. Departamento de Psicologia. III. Título.

CDD: 150 


\section{Agradecimentos}

Ao professor Marcus André Vieira, por sua orientação atenciosa e por me mostrar que é sempre possível ir um pouco além.

À professora Angélica Bastos por me conduzir desde meus primeiros passos na Psicanálise.

À minha avó e à minha tia, Norma e Maria, pelo tanto que investiram em mim, dando-me meios para que eu pudesse seguir minhas escolhas. Obrigada por todo o amor e por serem minhas principais referências.

Ao Rafael por toda a força, compreensão e paciência, por estar sempre comigo e por tolerar minhas ausências.

Aos amigos que estiveram presentes com sua escuta e suas palavras, especialmente à Giselle Rabelais, pelo auxílio e companhia virtual em algumas madrugadas de escrita.

À Ana Maria Mendonça, pelo apoio, pela confiança no meu trabalho e aposta em minha formação.

A CAPES, pelo apoio financeiro concedido durante o curso de mestrado. 


\section{Resumo}

Vieira, Norma Cavalcanti Pontilhão; Vieira, Marcus André (Orientador). Da neurose de angústia ao pânico: sobre as angústias atuais. Rio de Janeiro, 2012. 107p. Dissertação de Mestrado - Departamento de Psicologia, Pontifícia Universidade Católica do Rio de Janeiro.

Desde seus primeiros trabalhos, Freud dedicou-se à questão da angústia, da qual fazemos tema deste trabalho. Sua teoria sobre este afeto, no entanto, foi sendo submetida a uma série de revisões. Parece-nos permear este percurso uma articulação constante entre a angústia e um excesso impossível de representar que invade o sujeito nesta experiência. A fim de estabelecer as bases dessa leitura, percorremos em Freud e Lacan textos fundamentais sobre este afeto, enfatizando o que ali encontramos que deponha a favor da hipótese de uma aproximação entre angústia e excesso, que Freud, posteriormente, veio a articular como o além do princípio do prazer e que Lacan chamou de gozo. Na última e definitiva elaboração freudiana acerca da angústia, ela é considerada sinal diante de um perigo. Este perigo, em última instância, perigo de retorno de uma situação de desamparo psíquico, Lacan o formula como objeto $a$, o objeto da angústia. A relação da angústia com um objeto, longe de estar dada desde o início, foi sendo construída a partir das indicações do caráter real desta vivência, algo inominável e inapreensível pela teoria do recalque, mas que, por outro lado, representava um algo diante de que se angustiar. A despeito da crescente medicalização e da oferta de soluções rápidas para aplacar a angústia, a clínica contemporânea tem mostrado que essa questão está longe de perder relevância. Suas manifestações nos dias de hoje, no entanto, vêm apresentando a angústia muito mais em sua face traumática que em sua função de defesa. No lugar das fobias clássicas, as crises de pânico sem explicação. Vejamos de que modo a abordagem da angústia como experiência que testemunha a dimensão do real pode contribuir para a clínica contemporânea, especialmente no que concerne ao pânico.

\section{Palavras-chave}

Angústia; perigo; objeto $a$; gozo; pânico. 


\section{Abstract}

Vieira, Norma Cavalcanti Pontilhão; Vieira, Marcus André (Advisor). From anxiety neurosis to panic: about nowadays anguishes. Rio de Janeiro, 2012. 107p. MSc Dissertation - Departamento de Psicologia, Pontifícia Universidade Católica do Rio de Janeiro.

From his early work, Freud devoted himself to the issue of anguish, which is the theme of this work. His theory on this affect, however, was being subjected to a series of reviews. A constant discussion between anguish and an unrepresentable excess that pervades the subject seem to be around this study. In order to establish the basis of this reading, we have examined some important texts from Freud and Lacan, pointing out what we have found there to testify in favor of the hypothesis of an approach between anguish and excess, which Freud later articulated as the beyond the pleasure principle and what Lacan called jouissance. In the last and final freudian elaboration about the anguish, it was considered a sign of danger, as a risk of returning to a psychic state of helplessness. Lacan formulates this danger as the object $a$, the object of anguish. The relation of the anguish to an object, far from being established from the outset, was being made from the indication of the real nature of this experience, something unnamable and ungraspable by the theory of repression, but that, on the other hand, represented something up against which we should be anguished. Despite the increasing medicalization and the offers of quick solutions to ease the anguish, the contemporary clinic has shown that this issue is far from losing its relevance. Although, its current manifestations have been presenting the anguish in a much more traumatic way than in its function of defense. Instead of the classical phobias, there are panic attacks without explanation. We are going to see how the approach of anguish as an experience wich testifies the dimension of the real can contribute to the contemporary clinic, especially in relation to panic.

\section{Keywords}

Anguish; danger; object $a$; jouissance; panic. 


\section{Sumário}

Introdução

1. Angústia e recalque na primeira tópica freudiana: articulações e disjunções

1.1. Breves considerações sobre o afeto em Freud

1.2. A abordagem do adoecimento psíquico a partir da esfera somática: as neuroses atuais

1.3. A angústia articulada à trama dos conceitos metapsicológicos

2. A segunda teoria da angústia e a noção de perigo

2.1. A virada de 1920: o trauma e o além do princípio do prazer

2.2. A segunda teoria da angústia: inibição, sintoma e angústia

3. A construção do objeto: um percurso de Freud a Lacan 61

3.1. O objeto como perdido: a experiência de satisfação

3.2. O objeto como estranho: das Ding

3.3. Algumas considerações sobre o objeto $a$

4. Angústia: tradução subjetiva do objeto $a$

4.1. Aparições, aproximações e separações: da perturbação do imaginário à angústia constitutiva

4.2. Angústia: o pré-sentimento

4.3. Angústia na clínica contemporânea: os ataques de pânico

Considerações finais 
Agonizo, se tento Retomar a origem das coisas. Sinto-me dentro delas e fujo, Salto para o meio da vida.

(Angústia. João Ricardo e João Apolinário).

A angústia é correlativa do momento em que o sujeito está suspenso entre um tempo em que ele não sabe mais onde está, em direção a um tempo onde ele será alguma coisa na qual jamais se poderá reencontrar.

(Lacan, 1956-1957, p. 231). 